\title{
Properties of cellular and serum forms of thymidine kinase 1 (TK1) in dogs with acute lymphocytic leukemia (ALL) and canine mammary tumors (CMTs): implications for TK1 as a proliferation biomarker
}

\author{
Kiran Kumar Jagarlamudi ${ }^{1}$, Sara Westberg ${ }^{2}$, Henrik Rönnberg ${ }^{3^{*}}$ and Staffan Eriksson ${ }^{1}$
}

\begin{abstract}
Background: Thymidine kinase 1 (TK1) is a deoxyribonucleic acid (DNA) precursor enzyme and a proliferation biomarker used for prognosis and treatment monitoring of breast cancer in humans. The aim was to determine if serum thymidine kinase 1 (STK1) activity and sTK1 protein levels in dogs with mammary tumors could be useful in veterinary medicine.

Results: Serum samples from 20 healthy dogs and 27 dogs with mammary tumors were analyzed for sTK1 activity, using an $\left[{ }^{3} \mathrm{H}\right]$-deoxythymidine (dThd) phosphorylation assay, and for sTK1 protein levels by immune affinity/Western blot assay. The molecular forms of sTK1 in acute lymphocytic leukemia (ALL), canine mammary tumor (CMT), and healthy sera were determined by size exclusion chromatography.

Mean sTK1 activities in CMT were $1.0 \pm 0.36 \mathrm{pmol} / \mathrm{min} / \mathrm{mL}$, differing significantly from healthy dogs (mean $\pm \mathrm{SD}=0.73 \pm 0.26 \mathrm{pmol} / \mathrm{min} / \mathrm{mL}$ ). Serum TK1 protein (26 kDa polypeptide) levels were also significantly higher in CMTs compared to healthy dogs (mean $\pm \mathrm{SD}=28.5 \pm 11.4$, and $8.5 \pm 4 \mathrm{ng} / \mathrm{mL}$, respectively). Cellular TK1 isolated from ALL tumor cells was predominantly a dimer, while the serum TK1 activity eluted as a high molecular weight (MW) oligomer. In analyses of CMT tissue extracts, TK1 activity eluted in two peaks, a minor peak with a high MW oligomer and a major tetramer peak. Western blot analysis of chromatographic fractions showed that cellular TK1 protein in both ALL and CMT dogs, and to some extent serum TK1 from ALL dogs, correlated with activity profiles, but a large fraction of inactive TK1 protein was detected in CMT.

Conclusions: Serum TK1 protein and activity levels were significantly higher in CMT than in healthy dogs. Size exclusion chromatography demonstrated major differences in the molecular forms of sTK1 in ALL, healthy, and CMT dogs, with a large fraction of inactive TK1 protein in CMT. Our results showed that the sTK1 protein assay can differentiate benign tumors (early stage tumors) from healthy more efficiently than sTK1 activity assay. This preliminary data supports that sTK1 protein assay is clinically useful. Further studies are needed to evaluate the diagnostic or prognostic role of serum TK1 protein in CMTs.
\end{abstract}

Keywords: Canine serum thymidine kinase 1, sTK1 protein assays, Canine mammary tumors, Size exclusion chromatography, Anti-dog TK1 antibodies

\footnotetext{
* Correspondence: henrik.von.euler@slu.se

${ }^{3}$ Center of Clinical Comparative Oncology (C3O), Department of Clinical

Sciences, Swedish University of Agricultural Sciences, P.O. Box 7054, S-750 07

Uppsala, Sweden

Full list of author information is available at the end of the article
}

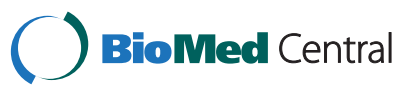

(c) 2014 Jagarlamudi et al.; licensee BioMed Central Ltd. This is an Open Access article distributed under the terms of the Creative Commons Attribution License (http://creativecommons.org/licenses/by/4.0), which permits unrestricted use, distribution, and reproduction in any medium, provided the original work is properly credited. The Creative Commons Public Domain Dedication waiver (http://creativecommons.org/publicdomain/zero/1.0/) applies to the data made available in this article, unless otherwise stated. 


\section{Background}

Mammary tumors are the most common form of canine tumors and account for approximately $50 \%$ of all tumors in female dogs $[1,2]$. Development of canine mammary tumors (CMTs) is influenced by age, hormone and genetic predispositions. CMTs are commonly seen in bitches at middle and old age, with a median age of 8-10 years [3-5]. Purebreed dogs have higher incidence of CMT [6] and breeds like Poodles, English Springer Spaniels (ESSs), German Shepherds, Boxers, and Dachshunds have a higher risk of developing CMT [1]. Overall, human and dog cancer diseases show similarities in terms of the role of steroidal hormones during tumor development, and correlation between tumor grade and rate of metastasis $[7,8]$. A recent study has shown that variations in the BRCA1 and BRCA2 genes are associated with CMT in ESSs [9] and these genes are responsible for early onset of breast cancer in women. Inherited mutations in BRCA1 or BRCA2 increase the risk of breast cancer in women by around $56-84 \%[10,11]$. The clinical impact and outcome of having BRCA mutations is somewhat unclear in humans [12-15]. BRCA1-associated breast cancers often occur in younger women, and these tumors are high grade and lack estrogen receptors (ERs), and are often triple-negative and, as such, harder to treat [16]. In dogs, overexpression of BRCA1 and BRCA2 has been found in mammary adenocarcinomas and their lymph node metastases, hence implying a tendency to reflect grade of malignancy [17]. Nevertheless, comparative breast cancer studies are likely to greatly benefit both human and veterinary medicine.

Early detection of CMTs and efficient therapy can increase the life span in dogs [18-20]. Several tumor markers, such as carbohydrate antigen 15-3 (CA 15-3), thymidine kinase 1 (TK1), carcinoembryonic antigen (CEA), estrogen receptor (ER), and human epidermal growth factor receptor 2 (HER-2/neu), have been evaluated for their capacity to aid in the diagnosis, prognosis, and monitoring of breast cancer in humans [21-24]. Some of these markers, like CA 15-3, CEA, ER, and HER-2, have been clinically evaluated in dogs [25-27], but investigations on TK1 in CMTs are largely lacking.

Thymidine kinase (TK) is a cytosolic enzyme that catalyzes the conversion of deoxythymidine (dThd) to deoxythymidine monophosphate (dTMP), which is subsequently phosphorylated to di- and triphosphates via the salvage pathway [28]. Thymidine kinase 1 is cell cycledependent and $S$ phase-specific. The TK1 activity reaches a peak G1/S boundary and then decreases rapidly in G2 and becomes undetectable in $M$ phase [29,30]. In human medicine, serum TK1 (sTK1) activity level serves as biomarker for prognosis and monitoring treatment of lymphoma and leukemia [31-33]. Serum TK1 activity has been determined by using the commercially available TK-radioenzyme assay (REA) [34] and non-radiometric TK-Liaison assay [35]. These activity-based assays provide valuable information regarding prognosis and treatment monitoring in canine lymphoma and leukemia [35,36]. A recent study on sera from dogs with solid tumors demonstrated that determination of sTK1 protein levels with immunochemical methods gave higher sensitivity compared to TK1 activity measurements [37].

To date, no studies exist where both TK1 activity and TK1 protein levels have been determined in sera from CMT patients. In this study, we analyzed TK1 activity and TK1 subunit $26 \mathrm{kDa}$ protein levels in sera from 27 dogs with CMTs. We further characterized the molecular forms of TK1 in ALL, CMT, and healthy dog sera using size exclusion chromatography. In the case of ALL, it was possible to study the cellular form of TK1 isolated from the leukemic cells, as in the CMT tissue extract. To our knowledge, this is the first time that cellular and serum forms of TK1 from the same patient have been determined.

\section{Methods}

\section{Serum samples}

Sera from healthy dogs and dogs with mammary tumors were collected from the University Animal Hospital at the Swedish University of Agricultural Sciences, Uppsala, Sweden, and stored at $-20^{\circ} \mathrm{C}$ until analysis. The project was approved by the Swedish Animal Ethics Committee and owner consent was collected for each patient. The study comprised samples from healthy dogs $(n=20)$ and dogs with mammary tumors $(n=27$ : benign $n=11$, malignant $\mathrm{n}=13$, and unclassified (UC) $\mathrm{n}=3$ ). The mean and median age was 6 years (range $3-10$ years) for the healthy group, and 9.5 and 9 years (range 3-14 years) for dogs with mammary tumors.

The tumor diagnostic procedures were as described previously [35]. A total of 20 breeds were included in this study. The most common breeds included were Labrador Retriever, Rottweiler, Boxer, and German Shepherd (5/47 of each), followed by Golden Retriever and Riesenschnauzer (4/47 each) Rhodesian Ridgebacks and mixed breed (3/47 of each), Bernese Mountain Dog and ESS (2/47 of each), Field Spaniel, Flatcoated Retriever, Border Collie, American Cocker Spaniel, Welsh Springer Spaniel, Belgian Shepherd, Dalmatian, Dachshund, and Greyhound (1/47 of each). Polyclonal antibodies were produced against different epitopes in the $\mathrm{C}$-terminal region of dog TK1. The 28-mer antibody was produced using a 28 amino acid synthetic peptide (amino acids 195-223) as antigen (Agrisera AB, Umeå, Sweden). The 16-mer antibody was produced against a 16 amino acid C-terminal region (amino acids 211-225) (GenScript, Piscataway, NJ, USA) [38]. 


\section{Isolation of acute lymphocytic leukemia cells and preparation of cell extract}

An amount of $4 \mathrm{ml}$ of heparinized ALL patient blood was diluted with an equal part of sterile phosphate-buffered saline (PBS) and the diluted blood sample was mixed with an equal volume of Ficoll-Paque. This was followed by centrifugation for 30 minutes at 1,500 revolutions per minute (RPMs). The cell band was removed, and washed three times with RPMI 1640 medium with L-glutamine containing $20 \%$ fetal calf serum (FCS) and $50 \mu \mathrm{g} / \mathrm{ml}$ gentamicin. The cell preparation contained at least 95\% ALL cells with a viability of $>98 \%$. Cell viability was estimated by using the Trypan blue exclusion assay. If the cells take up trypan blue it indicates that the cells are non-viable. Cell viability should be at least $>95 \%$ for healthy log-phase cells in cultures. Percentages of viable cells were determined by using the following formula:

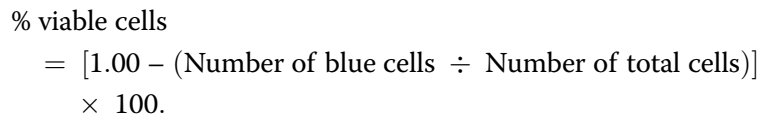

Cells $\left(16 \times 10^{6}\right)$ were lysed in buffer containing $10 \mathrm{mM}$ Tris/HCl, pH 7.6, $13.7 \mathrm{mM} \mathrm{NaCl} 7 \mathrm{mM}$ ethylenediaminetetraacetic acid (EDTA), 0.5\% NP-40, and $2 \mathrm{mM} \mathrm{4-2(ami-}$ noethyl)benzenesulfonyl fluoride hydrochloride (Pefabloc, Fluka, Seelze, Switzerland) for 30 minutes at $4^{\circ} \mathrm{C}$. The suspension was centrifuged at 13,000 RPMs for 10 minutes at $4{ }^{\circ} \mathrm{C}$ and supernatant was stored in aliquots at $-80^{\circ} \mathrm{C}$ after addition of $20 \%$ of glycerol. Protein concentration in the supernatant $(4 \mathrm{mg} / \mathrm{mL})$ was determined using the Bio-Rad assay.

\section{Extraction of thymidine kinase 1 from canine mammary tumor tissue}

Three grams of fresh tumor tissue (from dog No. 23) were collected from the clinic in sterile PBS, pH 7.6. The accuracy of the tumor diagnosis was confirmed by histopathological analysis of two flanking tissue preparations right adjacent to the tissue used for TK1 analysis. The TK1 enzyme extract was prepared as follows: The tissue was homogenized in a Teflon homogenizer with two volumes of $0.05 \mathrm{M}$ Tris-HCI buffer, $\mathrm{pH}$ 8.0, containing $0.34 \mathrm{M}$ sucrose, $25 \mathrm{mM} \mathrm{KCI}, 5 \mathrm{mM} \mathrm{MgCI} 2$, 7 mM EDTA, 0.5\% NP-40, and $2 \mathrm{mM}$ 4-2(aminoethyl) benzenesulfonyl fluoride hydrochloride (Pefabloc, Fluka, Seelze, Switzerland). The homogenate was centrifuged at 20,000 RPMs for 30 minutes. The supernatant with a protein concentration of $3 \mathrm{mg} / \mathrm{mL}$ was stored at $-20^{\circ} \mathrm{C}$ for further analysis.

\section{Serum thymidine kinase activity assay}

Thymidine kinase 1 activity in serum samples was determined using an optimized $\left[{ }^{3} \mathrm{H}\right]$-dThd phosphorylation assay, as described previously [36]. In brief, this assay is based on a radio enzymatic technique in which the substrate ${ }^{3}[\mathrm{H}]$-thymidine is converted to ${ }^{3}[\mathrm{H}]$-thymidine monophosphate by TK1 in serum. The TK1 activity is expressed as pmol of dTMP formed per minute per $\mathrm{mL}$ of serum.

\section{Immunoaffinity Sepharose preparation}

The purified polyclonal anti-dog TK1 antibody (16-mer) was coupled to cyanogen bromide $(\mathrm{CNBr})$-activated Sepharose 4B, as described previously [37]. Briefly, $2 \mathrm{mg}$ of purified 16-mer antibody was added per $1 \mathrm{~g}$ of the CNBr-activated Sepharose 4B resin in $0.1 \mathrm{M}$ sodium bicarbonate $\left(\mathrm{NaHCO}_{3}, \mathrm{pH}=8.3\right)$ on agitation for 4 hours at room temperature. Then the coupled Sepharose was transferred into Tris- $\mathrm{HCl}$ buffer $(0.1 \mathrm{M}, \mathrm{pH}$ 8.0) after 2 hours at room temperature. The resin was washed alternately three times with acetate buffer $(0.1 \mathrm{M}, \mathrm{pH} 4.0)$ and Tris- $\mathrm{HCl}$ buffer (0.1 M, pH 8.0). The coupled antibody-Sepharose was mixed with Tris-buffered saline (TBS) containing $0.01 \% \mathrm{NaN}_{3} 1: 1$, and stored at $4^{\circ} \mathrm{C}$.

\section{Size exclusion chromatography}

Size exclusion chromatography was performed as described elsewhere [38,39] using a Superose 12 column $(1.0 \times 30 \mathrm{~cm}$; GE Healthcare, Uppsala, Sweden) attached to fast protein liquid chromatography (FPLC) equipment (GE Healthcare, Uppsala, Sweden). Acute lymphocytic leukemia cell extract, ALL sera $(100 \mu \mathrm{l})$, CMT tissue extract, CMT sera (from dog No. 23), and sera from a healthy dog (No. 5) $(200 \mu \mathrm{l})$ were diluted in hydroxyethylpiperazineethane-sulfonic acid (HEPES), pH 7.6, buffer $(0.01 \mathrm{M})\left(\mathrm{NH}_{4} \mathrm{Cl}, 0.15 \mathrm{M}\right.$, and $\left.\mathrm{NaN}_{3}, 0.02 \%\right)$ and applied on the column. Standard proteins were $\alpha 2$-macroglobulin, $720 \mathrm{kDa} ; \beta$-amylase, $200 \mathrm{kDa}$; bovine serum albumin (BSA), $66 \mathrm{kDa}$; ova albumin, $45 \mathrm{kDa}$; and horse myosin, $17 \mathrm{kDa}$.

\section{Thymidine kinase 1 (TK1) isolation by anti-TK1 antibody Sepharose}

Dog recombinant TK1 (0.5-4 ng), $60 \mu \mathrm{L}$, serum samples were diluted with TBS, $\mathrm{pH} 7.6$, to a final volume of $230 \mu \mathrm{L}$. Next, $300 \mu \mathrm{L}$ of FPLC fractions were incubated with anti-dog TK1 antibody Sepharose $(70 \mu \mathrm{L}$ of a 1:1 V/V mixture of antibody Sepharose and TBS). The samples were agitated at $4^{\circ} \mathrm{C}$ for 4 hours, followed by centrifugation for 1 minute at 13,000 RPMs. The antibody Sepharose was washed twice with TBS, once with TBS-Tween, and once more with TBS. Then, $30 \mu \mathrm{L}$ of sodium dodecyl sulfate polyacrylamide gel electrophoresis (SDS-PAGE) sample buffer (containing Tris-HCl, pH 6.8, 0.5 M; glycerol, 20\%; (w/v) SDS, 10\%; bromophenol blue, $0.1 \%$; and dithiothreitol (DTT), $10 \mathrm{mM}$ ) was added to the Sepharose before incubation at room temperature for 20 minutes, followed by centrifugation as above. The 
supernatants were heated at $95^{\circ} \mathrm{C}$ for 5 minutes and subjected to $12 \%$ SDS-PAGE, followed by electrophoretic transfer and Western blotting, as described previously $[37,38]$.

\section{Statistical analysis}

The TK1 activity and protein distribution in both groups were tested for normality using the D' Agostino and Pearson omnibus normality test. The majority of distributions were Gaussian and we used one way analysis of variance (ANOVA) followed by Tukey's multiple comparison post test to compare TK1 values across multiple groups. Pearson correlation coefficient $(r)$ was used to determine the correlation between TK1 activities and TK1 protein levels. Unpaired $t$-test was used to evaluate the difference between the groups. For sensitivity and specificity analysis and for comparison of assays, receiver operating characteristic (ROC) curves were constructed. Statistical analyses were performed using Graph Pad Prism 5.0 (Graph Pad Software, La Jolla, CA, USA). The level of significance was set at $\mathrm{P}<0.05$.

\section{Results}

Serum thymidine kinase 1 activity and protein levels in canine mammary tumor

Sera from 20 healthy dogs and 27 CMT dogs were analyzed for sTK1 activity and sTK1 protein, as described in the Materials and Methods section. The intensities of the $28 \mathrm{kDa}$ recombinant dog TK1 polypeptide $(0.5-4 \mathrm{ng})$ were analyzed and a standard curve was created, as shown in Figure 1. Serum TK1 protein levels in clinical samples were calculated using this curve. In the healthy group, sTK1 activity was in the range of $0.4-1.4 \mathrm{pmol} / \mathrm{min} / \mathrm{mL}$, with a mean \pm standard deviation (SD) of $0.73 \pm 0.26$ (Table 1). In the immunoaffinity/Western blot analysis, faint bands were detected in sera from healthy dogs, with a range of $3-18 \mathrm{ng} / \mathrm{mL}$ (mean $\pm \mathrm{SD}$ of $8.5 \pm 4 \mathrm{ng} / \mathrm{mL}$; Figure 2A). In the CMT group, the sTK1 activity was $0.5-2.5 \mathrm{pmol} / \mathrm{min} / \mathrm{mL}$ (mean $\pm \mathrm{SD}=1.0 \pm 0.36)$. High sTK1 protein levels were found in the mammary tumor sera (Figure 2B) and the sTK1 protein concentration ranged from $9 \mathrm{ng} / \mathrm{mL}$ to $54 \mathrm{ng} / \mathrm{mL}$ (mean \pm SD of $28.5 \pm$ 11.4; Table 2). Serum TK1 protein levels in the ALL serum (36 ng/mL; Figure 2C), ALL extract (20 ng/mL; Figure 2D), and CMT extract $(34 \mathrm{ng} / \mathrm{mL}$; Figure $2 \mathrm{E})$ were also determined.

Significant differences were found in mean sTK1 activity $(\mathrm{P}=0.007$; Figure $3 \mathrm{~A})$ and sTK1 protein levels $(\mathrm{P}<0.0001$; Figure $3 \mathrm{~B}$ ) between healthy and CMT dogs. Significant correlations were also found between the sTK1 activity and sTK1 protein levels in healthy dogs $(r=0.52, \mathrm{P}=0.01)$ and CMTs $(r=0.41, \mathrm{P}=0.03)$. Canine mammary tumors were further classified as benign or malignant and the sTK1 protein and activity levels were determined in these
A)

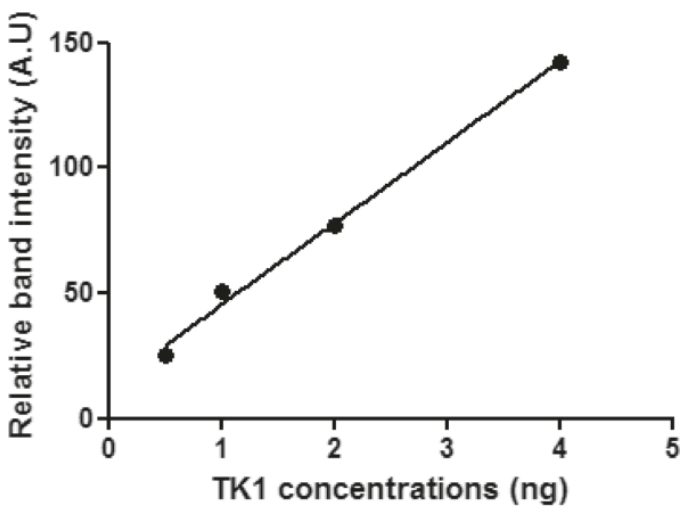

B)

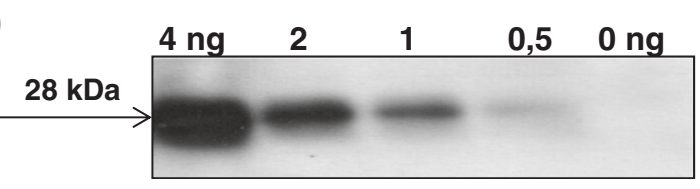

Figure 1 Standard curve for recombinant TK1 protein using the immune affinity assay and Western blot analysis. (A) Concentration curve obtained after scanning the relative band intensities (arbitrary units (AUs)). (B) The $28 \mathrm{kDa}$ polypeptide bands of recombinant dog thymidine kinase 1 (TK1) (0.5-4 ng).

subgroups and compared to those in healthy dogs. There was no significant difference in sTK1 activity in sera from healthy, benign, and malignant dogs (Figure 3C). However, a significant difference was found in sTK1 protein levels between these subgroups (Figure 3D). To evaluate the performance of the two different assays, ROC curve analysis for CMTs vs. healthy dogs was done. The results showed that TK1 activity assay had an area under the curve (AUC) of $0.74, \mathrm{P}=0.0048$ (95\% confidence interval (CI) $0.59-0.88)$, with a cutoff value of $1.32 \mathrm{pmol} / \mathrm{min} / \mathrm{mL}$, sensitivity of 0.22 , and specificity of 0.95 (Figure $4 \mathrm{~A}$ ). The TK1 protein assay, however, had an AUC of 0.96, $\mathrm{P}<0.0001$ (95\% CI $0.92-1.01$ ). The sensitivity in this case was 0.81 and the specificity 0.95 , using a cutoff value of $17.5 \mathrm{ng} / \mathrm{mL}$ (Figure $4 \mathrm{~B}$ ). The specific activity of sTK1 (nmol dTMP/min/mg of sTK of $26 \mathrm{kDa})$, based on the immunoaffinity assay and ${ }^{3}[\mathrm{H}]$-dThd activity measurements in healthy dogs, was $49 \pm 21 \mathrm{nmol} / \mathrm{min} / \mathrm{mg}$, which is significantly higher $(\mathrm{P}<0.0001)$ compared to sera from the CMT group $(20 \pm 11 \mathrm{nmol} / \mathrm{min} / \mathrm{mg})$. The higher sTK1 specific activity in healthy dogs (about 2.5-fold), compared to dogs with CMTs, means that there is a larger fraction of inactive TK1 polypeptide in case of CMTs.

\section{Molecular forms of thymidine kinase 1 in acute lymphocytic leukemia extract and sera}

A fresh blood sample collected from a dog with ALL and white blood cells were separated, as described in the Materials and Methods section. Cellular extract and sera 
Table 1 Serum thymidine kinase 1 (sTK1) activity and sTK1 protein concentration in sera from healthy dogs

\begin{tabular}{|c|c|c|c|c|}
\hline Number & Breed & Age (yrs) & $\begin{array}{l}\text { sTK1 activity } \\
(\mathrm{pmol} / \mathrm{min} / \mathrm{mL}) \\
(\text { Mean } \pm \mathrm{SD})^{\mathrm{a}}\end{array}$ & $\begin{array}{l}\text { sTK1 concentration } \\
(\mathrm{ng} / \mathrm{mL}) \\
(\text { Mean } \pm \mathrm{SD})^{\mathrm{b}}\end{array}$ \\
\hline 1 & Labrador Retriever & 8 & $0.7 \pm 0.03$ & $3 \pm 1$ \\
\hline 2 & Bernese Mountain Dog & 10 & $1.0 \pm 0.05$ & $9 \pm 3$ \\
\hline 3 & Labrador Retriever & 5 & $0.5 \pm 0.04$ & $4 \pm 2$ \\
\hline 4 & Golden Retriever & 6 & $0.4 \pm 0.02$ & $7 \pm 3$ \\
\hline 5 & Golden Retriever & 5 & $1.0 \pm 0.06$ & $15 \pm 4$ \\
\hline 6 & German Shepherd & 6 & $1.0 \pm 0.1$ & $11 \pm 3$ \\
\hline 7 & Riesenschnauzer & 7 & $0.5 \pm 0.02$ & $4 \pm 2$ \\
\hline 8 & Mixed breed & 6 & $0.5 \pm 0.05$ & $12 \pm 5$ \\
\hline 9 & Riesenschnauzer & 8 & $0.6 \pm 0.04$ & $10 \pm 4$ \\
\hline 10 & German Shepherd & 6 & $0.7 \pm 0.08$ & $12 \pm 3$ \\
\hline 11 & Rottweiler & 5 & $0.5 \pm 0.03$ & $7 \pm 3$ \\
\hline 12 & English Springer Spaniel & 3 & $1.3 \pm 0.09$ & $8 \pm 2$ \\
\hline 13 & Riesenschnauzer & 7 & $1.4 \pm 0.12$ & $13 \pm 4$ \\
\hline 14 & Labrador Retriever & 5 & $0.8 \pm 0.07$ & $18 \pm 5$ \\
\hline 15 & Labrador Retriever & 6 & $0.7 \pm 0.03$ & $5 \pm 3$ \\
\hline 16 & Mixed breed & 6 & $0.6 \pm 0.01$ & $9 \pm 2$ \\
\hline 17 & Bernese Mountain Dog & 5 & $0.7 \pm 0.04$ & $8 \pm 3$ \\
\hline 18 & Dalmatian & 6 & $0.5 \pm 0.03$ & $4 \pm 2$ \\
\hline 19 & Labrador Retriever & 4 & $0.7 \pm 0.11$ & $8 \pm 3$ \\
\hline 20 & Golden Retriever & 6 & $0.5 \pm 0.04$ & $6 \pm 2$ \\
\hline
\end{tabular}

${ }^{\mathrm{a}}$ Mean values of three observations from a single measurement occasion. ${ }^{\mathbf{b}}$ Mean values of two observations from two independent experiments. $\mathrm{SD}=$ standard deviation.

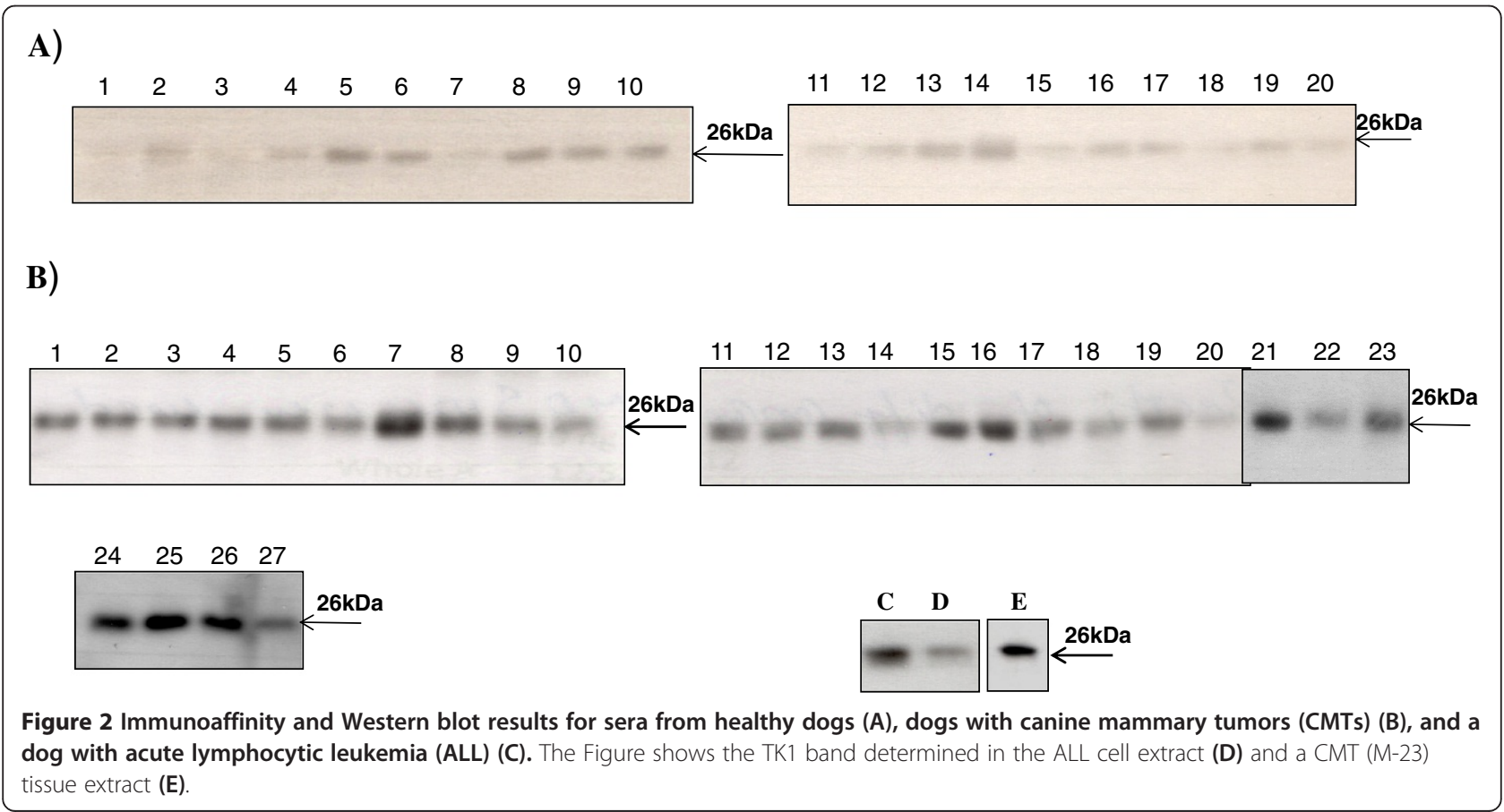


Table 2 Serum thymidine kinase 1 (sTK1) activity and protein levels in sera from dogs with mammary tumors

\begin{tabular}{|c|c|c|c|c|c|}
\hline Number & Breed & Age (yrs) & Diagnosis & $\begin{array}{l}\text { sTK1 activity } \\
(\mathrm{pmol} / \mathrm{min} / \mathrm{mL}) \\
(\text { Mean } \pm \mathrm{SD})^{\mathrm{a}}\end{array}$ & 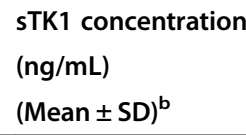 \\
\hline 1 & Field Spaniel & 9 & Mammary adenoma & $0.8 \pm 0.04$ & $26 \pm 4$ \\
\hline 2 & Rhodesian Ridgeback & 11 & Mammary adenoma & $0.9 \pm 0.03$ & $26 \pm 5$ \\
\hline 3 & Rhodesian Ridgeback & 3 & Mammary adenoma & $0.6 \pm 0.02$ & $23 \pm 3$ \\
\hline 4 & Boxer & 13 & Mammary carcinoma & $0.9 \pm 0.04$ & $27 \pm 2$ \\
\hline 5 & American Cocker Spaniel & 11 & Mammary carcinoma & $0.9 \pm 0.05$ & $27 \pm 5$ \\
\hline 6 & Boxer & 9 & Mammary carcinoma & $0.6 \pm 0.03$ & $21 \pm 4$ \\
\hline 7 & Welsh Springer Spaniel & 9 & Mammary carcinoma & $1.6 \pm 0.11$ & $54 \pm 8$ \\
\hline 8 & English Springer Spaniel & 10 & Mammary adenoma & $1.5 \pm 0.14$ & $35 \pm 5$ \\
\hline 9 & German Shepherd & 7 & Mammary carcinoma & $0.7 \pm 0.03$ & $23 \pm 3$ \\
\hline 10 & Belgian Shepherd & 9 & UC & $0.5 \pm 0.01$ & $17 \pm 3$ \\
\hline 11 & Riesenschnauzer & 14 & Mammary carcinoma & $0.9 \pm 0.02$ & $30 \pm 3$ \\
\hline 12 & Boxer & 11 & Mammary adenoma & $1.4 \pm 0.1$ & $27 \pm 4$ \\
\hline 13 & Boxer & 7 & Mammary carcinoma & $1.2 \pm 0.15$ & $31 \pm 5$ \\
\hline 14 & Rottweiler & 9 & Mammary adenoma & $0.5 \pm 0.02$ & $12 \pm 3$ \\
\hline 15 & German Shepherd & 11 & Mammary adenoma & $0.8 \pm 0.03$ & $39 \pm 6$ \\
\hline 16 & Dachshund & 9 & Mammary carcinoma & $0.9 \pm 0.04$ & $49 \pm 5$ \\
\hline 17 & Greyhound & 12 & UC & $1.8 \pm 0.18$ & $28 \pm 4$ \\
\hline 18 & Rhodesian Ridgeback & 11 & Mammary adenoma & $1.0 \pm 0.06$ & $17 \pm 3$ \\
\hline 19 & Rottweiler & 10 & Mammary adenoma & $0.9 \pm 0.05$ & $28 \pm 2$ \\
\hline 20 & Boxer & 8 & UC & $0.7 \pm 0.04$ & $9 \pm 2$ \\
\hline 21 & Rottweiler & 10 & Mammary carcinoma & $0.9 \pm 0.04$ & $40 \pm 8$ \\
\hline 22 & Rottweiler & 7 & Mammary adenoma & $0.7 \pm 0.05$ & $18 \pm 5$ \\
\hline 23 & German Shepherd & 10 & Mammary carcinoma & $1.3 \pm 0.08$ & $31 \pm 7$ \\
\hline 24 & Golden Retriever & 8 & Mammary carcinoma & $1.5 \pm 0.12$ & $43 \pm 9$ \\
\hline 25 & Flatcoated Retriever & 6 & Mammary adenoma & $1.0 \pm 0.09$ & $28 \pm 5$ \\
\hline 26 & Mixed breed & 6 & Mammary carcinoma & $1.1 \pm 0.08$ & $49 \pm 10$ \\
\hline 27 & Border Collie & 14 & Mammary carcinoma & $1.6 \pm 0.14$ & $13 \pm 4$ \\
\hline
\end{tabular}

${ }^{a}$ Mean values of three observations from a single measurement occasion. ${ }^{b}$ Mean values of two observations from two independent experiments. SD $=$ standard deviation. Mammary tumors are classified as adenoma (benign), carcinoma (malignant), and UC = unclassified.

from the same dog were applied to the Superose 12 column and the TK1 activity and protein levels in the fractions were determined. Native cellular TK1 activity eluted as major peak with molecular weights (MWs) of 40-66 kDa, but with a small peak and some enzyme activity in the fractions at the higher MW range (Figure 5A). Western blot analysis of cellular extract fractions showed a TK1 subunit $(26 \mathrm{kDa})$ in the fractions eluted, corresponding to MWs of 40-66 kDa, with faint bands in the high MW region (Figure 5B). When analyzing sera from the same dog, about $90 \%$ of TK1 eluted as a peak in the high MW range corresponding to $200-720 \mathrm{kDa}$ (Figure 5C). A TK1 polypeptide of $26 \mathrm{kDa}$ was detected in fractions $1-12$, but the band intensity did not correlate with the activity levels in these fractions (Figure 5D).
These results indicate that active cellular TK1 isolated from ALL exists mainly as dimer, while active sTK1 from the same dog was found to occur as a high MW oligomer. A gel filtration experiment has been carried out with sera from another ALL dog and similar results were found (data not shown).

\section{Molecular forms of thymidine kinase 1 in mammary tumor extract and sera}

Tissue extract prepared from a CMT patient (No. 23) was applied on the Superose 12 column and around 70\% of total TK1 activity eluted as major peak with MWs of 40-100 kDa, but with a minor peak and some enzyme activity in the fractions corresponding to higher $\mathrm{MW}$ (Figure 6A). Western blot analysis of CMT extract showed 

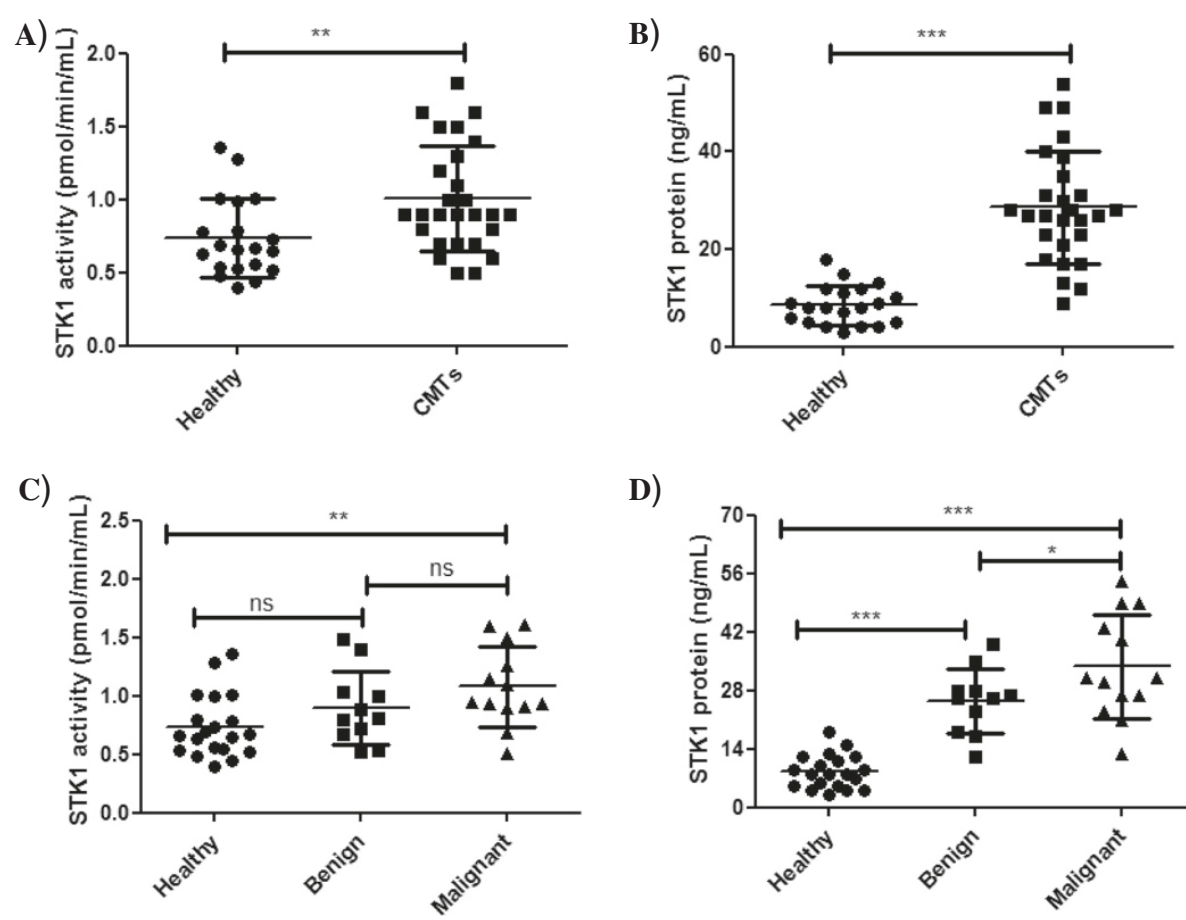

D)

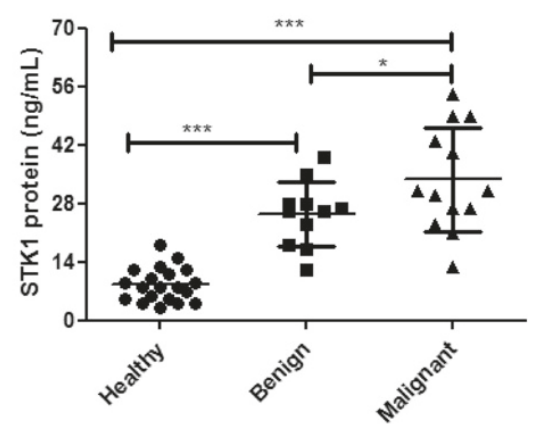

Figure 3 Serum TK1 activity and TK1 protein concentrations in different clinical samples. (A) Serum thymidine kinase 1 (sTK1) activity $(\mathrm{pmol} / \mathrm{min} / \mathrm{mL})$ in sera from healthy dogs $(\cdot)$ and dogs with mammary tumors $(\mathbf{(})$ ). The error bars represent means \pm standard deviation (SD). (B)

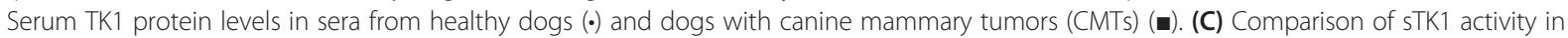

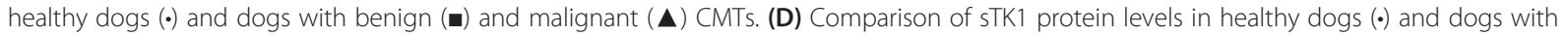
benign ( $\mathbf{-})$ and malignant $(\boldsymbol{\Delta})$ mammary tumors. The error bars represent means \pm standard deviation (SD).

a TK1 subunit $(26 \mathrm{kDa})$ in the fractions corresponding to the peak and faint bands in the high MW region (Figure 6B). A serum sample from the same CMT dog was also analyzed and more than $95 \%$ of the total TK1 activity eluted in fractions 1-11, corresponding to the MW range $200-720 \mathrm{kDa}$ (Figure $6 \mathrm{C}$ ). Thymidine kinase 1 polypeptide of $26 \mathrm{kDa}$ was detected in all fractions (Figure 6D) and there was no correlation with TK1 activity. These results indicate that sTK1 protein exists in multimeric forms in CMT (oligomers, dimers, and tetramers), many of them apparently inactive.

Molecular forms of thymidine kinase 1 in healthy dog sera A serum sample from a healthy dog (No. 5) was subjected to size exclusion chromatography. Thymidine kinase 1 activity was recovered as a single peak in fractions $1-5$, corresponding to a MW range of $500-720 \mathrm{kDa}$ (Figure $7 \mathrm{~A}$ ). Western blot analysis showed a TK1 polypeptide of $26 \mathrm{kDa}$
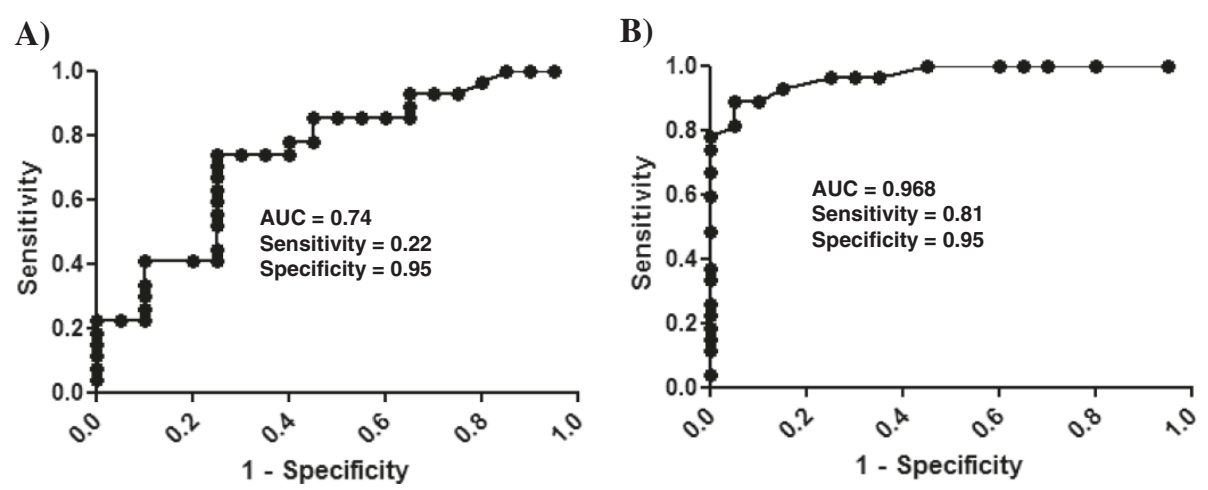

Figure 4 Receiver operating characteristic (ROC) curve for the serum thymidine kinase 1 (sTK1) in healthy and canine mammary sera. (A) sTK1 activity. (B) sTK1 protein assay results. 


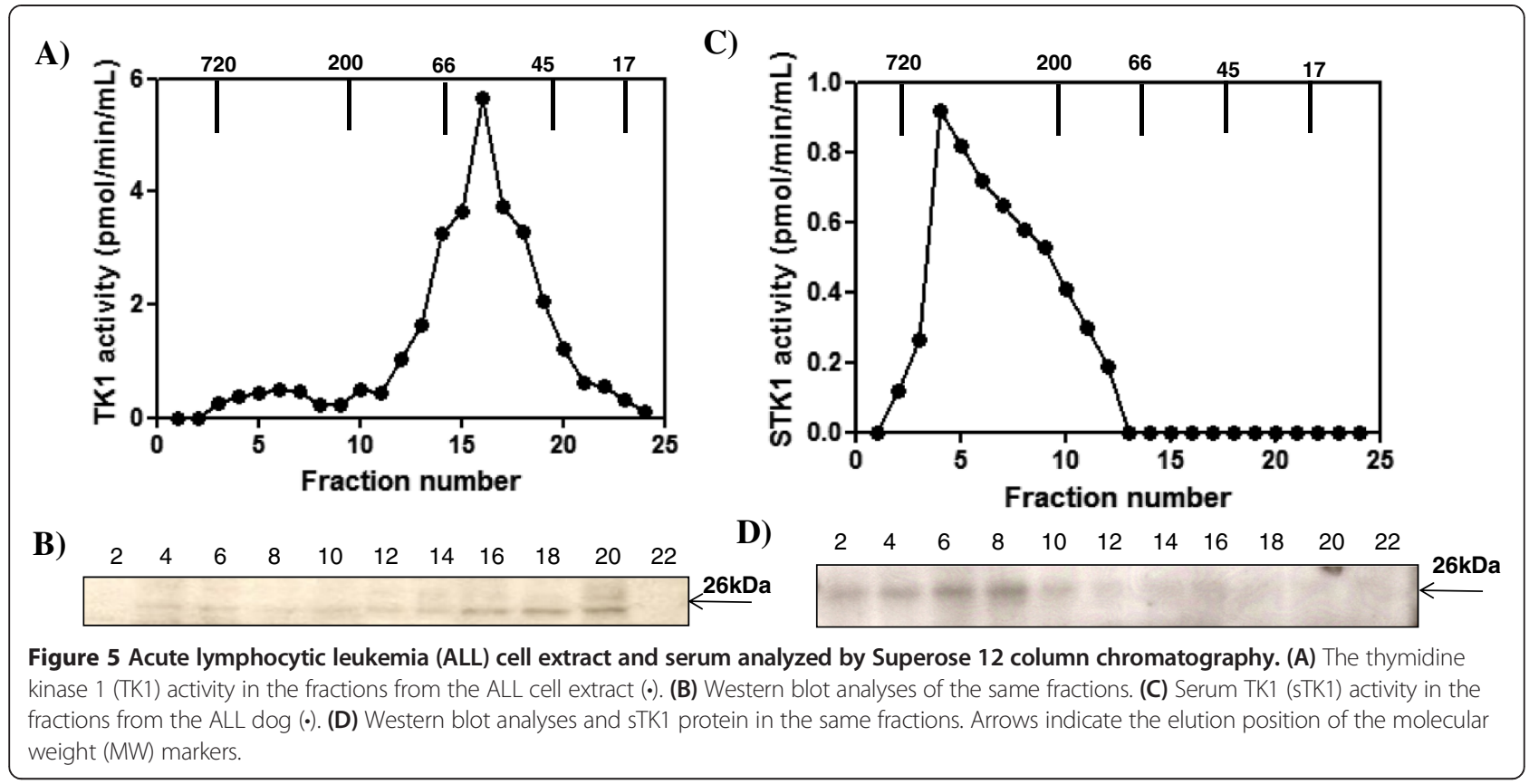

in the same fractions (Figure 7B). These results demonstrate that sTK1 exists as an active high MW oligomer in sera of healthy dogs. When we analyzed another healthy dog serum on superose 12 column, similar results were found (Figure 8).

\section{Discussion}

Serum TK1 determinations have been used clinically for many years as they provide valuable information to guide anti-cancer therapy both in human and in veterinary medicine. Development of antibody-based assays has extended the use of TK1 in human breast cancer. Some studies in humans have shown that breast cancer sera contain high sTK1 protein levels, which can serve as prognostic marker for early stage detection [24,40,41]. A recent study in dogs with solid tumors has shown that TK1 protein assays are more sensitive compared to TK1 activity assays [37]. Mammary tumors occur more frequently in

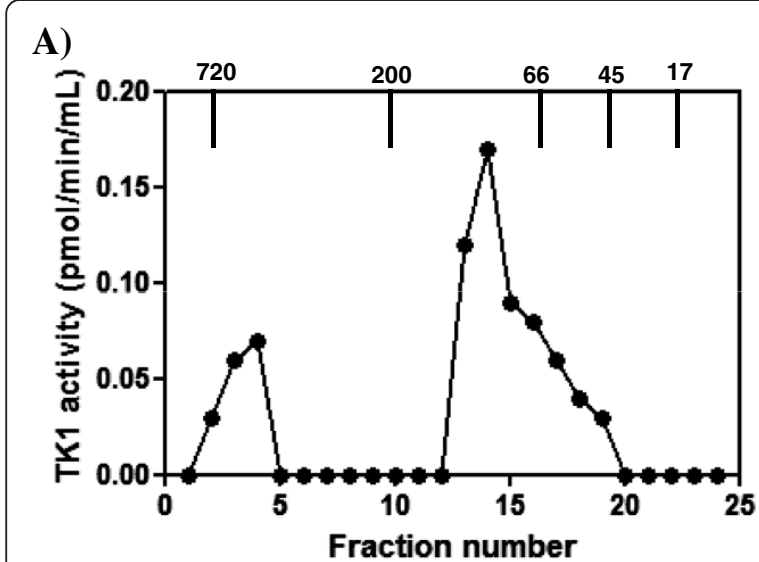

B) $\quad \begin{array}{llllllllllll}2 & 4 & 6 & 8 & 10 & 12 & 14 & 16 & 18 & 20 & 22 & 24\end{array}$

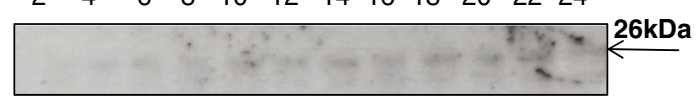

C)

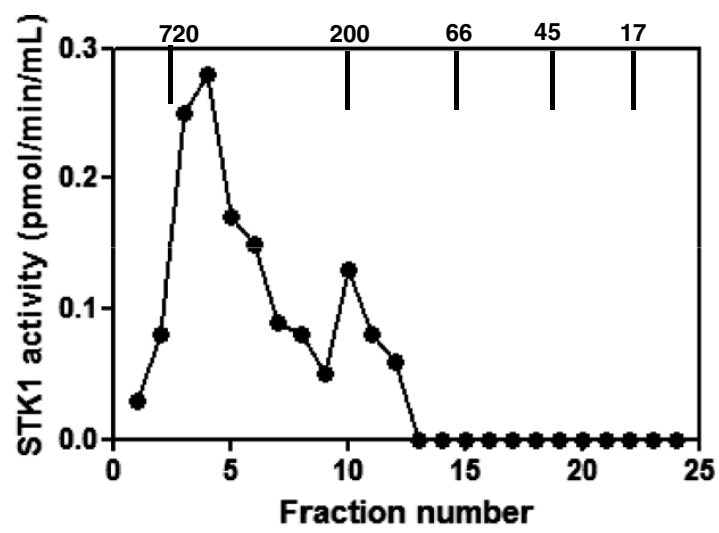

D)

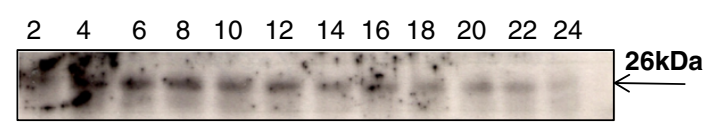

Figure 6 Canine mammary tumor (CMT) (dog No. 23) tumor tissue extract and serum analyzed by Superose 12 column chromatography. (A) Thymidine kinase 1 activity in the fraction from the CMT tissue extract (•). (B) Western blot analyses of the same fractions. (C) Thymidine kinase 1 activity in the fractions from the CMT serum (•). (D) Western blot analyses of the same fractions. Arrows indicate the elution position of the molecular weight (MW) markers. Numbers represent the fast protein liquid chromatography (FPLC) fractions. 
A)

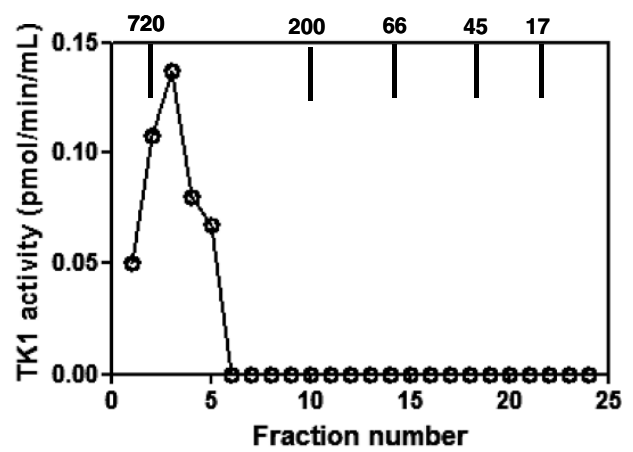

B)

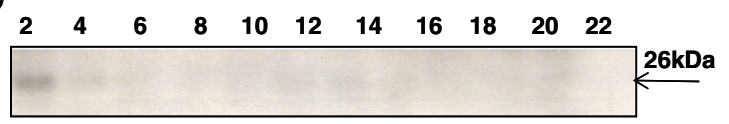

Figure 7 Serum from a healthy dog (No. 5) analyzed by Superose 12 column chromatography. (A) Serum thymidine kinase 1 (STK1) activity in the fractions from the healthy dog $(\cdot)$. (B) Western blot analyses of sTK1 protein in the same fractions. Arrows indicate the elution position of the molecular weight (MW) markers. Numbers represent the fast protein liquid chromatography (FPLC) fractions.

dogs than in other species and diagnosing patients during early stages of disease will be valuable clinically. In this study, we evaluated if sTK1 activity assay and TK1 protein assay can effectively differentiate CMT patients from healthy dogs.

A)

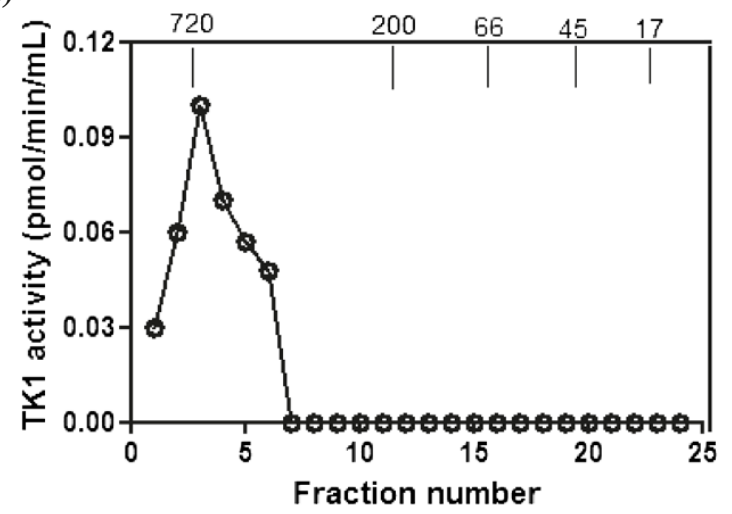

B)

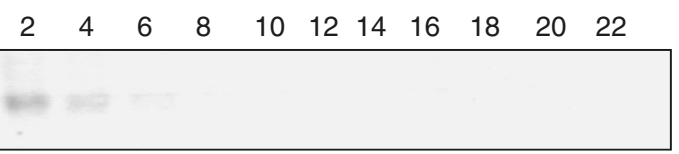

Figure 8 STK1 profile in FPLC fractions of another healthy dog (sample no. 14, See Table 1) (A) Serum thymidine kinase 1 (sTK1) activity in the fractions from the healthy dog (•). (B) Western blot analyses of sTK1 protein in the same fractions. Arrows indicate the elution position of the molecular weight (MW) markers. Numbers represent the fast protein liquid chromatography (FPLC) fractions.
The reason for comparing ALL and CMT was to show the difference in the molecular forms of TK1 in Hematological tumors (ALL) and solid tumors (CMT). In our last published study [38] we demonstrated the molecular forms of STK1 in an ALL patient and it was hence highly interesting to repeat these studies together with a characterization of the molecular forms of cellular (i.e. the tumor cells) TK1 from the same ALL patient. Furthermore, CMT are the most common tumors in older dogs and to develop an assay that can aid in the diagnosis of these types of tumors would be highly clinically valuable.

Even though sTK1 activity levels in CMTs significantly differ from levels in healthy dogs, there is a large overlap between levels in the two groups. The results presented here using sTK1 protein assays showed a larger difference and CMT patients had significantly higher sTK1 protein levels compared to healthy dogs. In this study, sTK1 protein assays were apparently able to differentiate benign from healthy samples as well as benign from the malignant forms of CMT, indicating that it may be possible to predict tumor progression by measuring sTK1 protein levels. Furthermore, the ROC curve analysis showed that the sTK1 protein assay had a sensitivity of 0.81 , while the sTK1 activity assay showed a sensitivity of 0.22 . Consequently, the sTK1 protein assay is most likely very valuable for establishing prognosis and early diagnosis in CMTs. Recently, expression analyses in CMTs have shown significant similarities to human breast cancer [42]. Consequently, it is suggested that these profiles can aid in prognosticating outcome [43,44]. However, these expression analyses are still complicated and most likely useful only as research tools. Moreover, they require specific, non-routine tissue preparation. A simple protein measurement in serum from a mammary tumor patient would be significantly easier to use and have a direct clinical implication. A natural next step in this research is to investigate if TK protein levels are correlated to, e.g., BRCA status in canine mammary tumors [9] and, if so, if TK protein level analysis is a suitable complement to more elaborate expression analyses of extirpated tumor tissue and is possible to perform before surgery. This could become a marker to gate patients into more, or less, aggressive surgical/medical interventions and could likely positively affect outcomes. It could also reduce surgical trauma in a fair portion of cases, which is ethically attractive. In the present study no correlation was tested between e.g. high/low grade in the CMT group because of low power. It is known that half of the malignant CMT (later) metastasize. Thus, it would be clinically highly beneficial if an early indication of the metastatic potential of the individual tumor could be made. The present study clearly indicates the need for prospective follow-up studies, where larger groups of CMTs are collected, with possibility to collect follow-up information on clinical outcome and 
compare histopathological grade and pre/post-op STK1 protein values to see if a decline in STK1 levels is seen post-op, further indicating the correlation between STK1 levels and CMT.

However, a lack of more detailed information about the molecular forms of sTK1 in dogs with tumor disease is a problem when it comes to using TK1 as a biomarker. In this study, we characterized cellular and serum forms of TK1. The cellular TK1 in ALL cells was found to exist mainly as active dimers, as reported previously $[38,45]$, while sTK1 occurs as high MW oligomeric complexes. There was no direct correlation between sTK1 protein and activity levels, as shown previously [38], and this was apparently due to the different types of TK1 protein complexes, with varying specific activity. Active TK1 in CMT cell extracts was mainly found as tetramers, while sTK1 activity occurred predominantly as high MW oligomers. The $26 \mathrm{kDa}$ TK1 protein levels were correlated to the activity in cell extract, but in case of sTK1, the $26 \mathrm{kDa}$ polypeptide was detected in all fractions corresponding to a broad range of MWs. In sTK1 in healthy dogs, where the levels were low, both TK1 activity and protein were detected only in the high MW region. There is a correlation between sTK1 activity and protein levels in sera from healthy dogs $(r=0.52)$ and sera from dogs with CMTs $(r=0.41)$. This is most likely because activity assays measure the high MW complex of TK1, whereas the TK1 protein assays measure both active high MW and inactive lower MW forms. There was a difference in the mean specific activities of sTK1 from healthy dogs, dogs with CMT, and the dog with ALL, namely, $49 \pm 21$, $20 \pm 10$, and $760 \pm 40 \mathrm{nmol} / \mathrm{min} / \mathrm{mg}$, respectively. The results obtained in this study are similar to those described earlier [37]. The specific activity of sTK1 was measured in a relatively large group of dogs with CMT and was found to be about half that of sTK1 in healthy dogs and about $2 \%$ of that observed in the ALL dog, which is very close to results observed with recombinant canine TK1 [38].

In this study, we have attempted to determine total tumor TK1 protein and activity levels as well as sTK1 levels in ALL and CMT dogs, using the same methods. There was a large difference in the ratio between the cellular and sTK1 total activity and $26 \mathrm{kDa}$ TK1 protein levels in the ALL and CMT dogs (both about 50-fold). The reason for these large differences is most likely related to the differences in specific activities of the cellular and serum form of TK1 and this in turn is linked to the mechanisms involved in the accumulation and release of TK1 from hematologic and solid tumors. However, further studies are needed to clarify this question.

Normally, TK1 is present in relatively low concentrations in blood from healthy dogs. It is $5-20$-fold in malignant diseases $[37,38]$. Therefore, sensitive laboratory methods are needed to obtain sufficient specificity and sensitivity.
With the current available enzyme activity assays, this was achieved only for hematological tumors. These enzyme activity assays were not sufficient for detecting mammary tumors in dogs. However, sTK1 protein assays differentiate CMTs from healthy dogs more effectively and improve the clinical precision. The work described here will help to develop a reliable TK1 clinical test, which could be valuable in veterinary medicine. Furthermore, with the similarities to human mammary tumors, it will likely have comparative implications in breast cancer research.

\section{Conclusions}

The results from this study show that TK1 protein assays provide more clinically relevant information on CMTs compared to TK1 activity assays. Size exclusion chromatography analysis demonstrates that sTK1 exists as a high MW complex form in dogs with ALL, healthy dogs, and dogs with CMT, with active enzyme. In addition, in sera from dogs with CMT, there is a large fraction of inactive TK1 in intermediate and low MW complexes. These results will help to develop better TK1 protein assays of value for human and veterinary medicine.

\section{Abbreviations \\ ALL: Acute lymphocytic leukemia; ANOVA: Analysis of variance; AUC: Area under the curve; BSA: Bovine serum albumin; Cl: Confidence interval; CMT: Canine mammary tumor; CNBr: Cyanogen bromide; DNA: Deoxyribonucleic acid; dThd: Deoxythymidine; dTMP: Deoxythymidine monophosphate; DTT: Dithiothreitol; EDTA: Ethylenediaminetetraacetic acid; FCS: Fetal calf serum; FPLC: Fast protein liquid chromatography; HEPES: Hydroxyethyl- piperazineethane-sulfonic acid; MW: Molecular weight; PBS: Phosphate-buffered saline; ROC: Receiver operating characteristic; RPM: Revolution per minute; RPMI: Roswell Park Memorial Institute; SD: Standard deviation; SDS: Sodium dodecyl sulfate; SDS-PAGE: Sodium dodecyl sulfate polyacrylamide gel electrophoresis; STK1: Serum thymidine kinase 1; TBS: Tris-buffered saline; TK: Thymidine kinase; TK1: Thymidine kinase 1.}

\section{Competing interests}

Staffan Eriksson is a co-inventor of a TK1 patent licensed to DiaSorin Inc. and a cofounder of, and shareholder in, Arocell AB. The other authors have no financial or personal relationship with any individuals or organizations that could inappropriately influence or bias the content of this article.

\section{Authors' contributions}

KKJ, HR, and SE designed this study. KKJ performed TK1 activity measurements in all serum samples, immunoblot analysis of sera, and statistical data analysis, and prepared the manuscript. Sample collection and clinical diagnosis were performed by SW and HR. SE and HR critically revised the manuscript. All authors have read and approved the final manuscript.

\section{Acknowledgements}

This study was supported by funds from the Swedish Research Council (S.E.), the Faculty of Veterinary Medicine and Animal Science, Swedish University of Agricultural Sciences (S.E.), and the companion animal insurance company AGRIA (H.v.E.). We would like to thank Dr. Liya Wang for providing the recombinant dog TK1.

\section{Author details}

'Department of Anatomy, Physiology, and Biochemistry, Swedish University of Agricultural Sciences, Biomedical Center, P.O. Box 575, S-751 23 Uppsala, Sweden. ${ }^{2}$ University Animal Hospital, Swedish University of Agricultural Sciences, P.O. Box 7040, S-750 07 Uppsala, Sweden. ${ }^{3}$ Center of Clinical Comparative Oncology (C3O), Department of Clinical Sciences, Swedish University of Agricultural Sciences, P.O. Box 7054, S-750 07 Uppsala, Sweden. 
Received: 5 May 2014 Accepted: 20 September 2014

Published online: 08 October 2014

\section{References}

1. Egenvall $A$, Bonnett BN, Ohagen P, Olson P, Hedhammar A, von Euler H: Incidence of and survival after mammary tumors in a population of over 80,000 insured female dogs in Sweden from 1995 to 2002. Prev Vet Med 2005, 69:109-127.

2. Sleeckx N, De rooster H, Veldhuis Kroeze EJB, Van Ginneken C, Van Brantegem L: Canine mammary Tumors, an overview. Reprod Dom Anim 2011, 46:1112-1131.

3. Hellmen E, Bergstrom R, Holmberg L, Spangberg IB, Hansson K, Lindgren A: Prognostic factors in canine mammary tumors: a multivariate study of 202 consecutive cases. Vet Pathol 1993, 30:20-27.

4. Chang SC, Chang CC, Chang TJ, Wong ML: Prognostic factors associated with survival two years after surgery in dogs with malignant mammary tumors: 79 cases (1998-2002). J Am Vet Med Assoc 2005, 227:1625-1629.

5. MacEwen EG, Withrow S, Ch 27: Tumors of the mammary gland. In Small Animal Clinical Oncology. 5th edition. Philadelphia: Saunders Company; 2013:538-556.

6. Schneider R: Comparison of age, sex, and incidence rates in human and canine breast cancer. Cancer 1970, 26:419-426.

7. Young $J \mathrm{Jr}$, Ward KC, Wingo PA, Howe HL: The incidence of malignant non-carcinomas of the female breast. Cancer Causes Control 2004 15:313-319.

8. Bostock DE: Canine and feline mammary neoplasms. Br Vet J 1986, 142:506-515.

9. Rivera $P$, Melin M, Biagi T, Fall T, Haggstrom J, Lindblad-Toh $K$, Von Euler $\mathrm{H}$ : Mammary tumor development in dogs is associated with BRCA1 and BRCA2. Cancer Res 2009, 69:8770-8774.

10. King MC, Marks JH, Mandell JB: Breast and ovarian cancer risks due to inherited mutations in BRCA1 and BRCA2. Science 2003, 302:643-646.

11. Eisen A, Lubinski J, Klijn J, Moller P, Lynch HT, Offit K, Weber B, Rebbeck T, Neuhausen SL, Ghadirian P, Foulkes WD, Gershoni-Baruch R, Friedman E, Rennert G, Wagner T, Isaacs C, Kim-Sing C, Ainsworth P, Sun P, Narod SA Breast cancer risk following bilateral oophorectomy in BRCA1 and BRCA2 mutation carriers: an international case-control study. J Clin Oncol 2005, 23:7491-7496

12. Stoppa-Lyonnet $D$, Ansquer $Y$, Dreyfus $H$, Gautier $C$, Gauthier-Villars $M$, Bourstyn E, Clough KB, Magdelenat H, Pouillart P, Vincent-Salomom A, Fourguet A, Asselain B: Familial invasive breast cancers: worse outcome related to BRCA1 mutations. J Clin Oncol 2000, 18:4053-4059.

13. Eerola H, Vahteristo P, Sarantaus L, Kyyrönen P, Pyrhönen S, Blomqvist C, Pukkala E, Nevanlinna H, Sannkila R: Survival of breast cancer patients in BRCA1, BRCA2 and non-BRCA1/2 breast cancer families: a relative survival analysis from finland. Int J Cancer 2001, 93:368-372.

14. Goffine JR, Chappuis PO, Begin LR, Wong N, Brunet JS, Hamel N, Paradis AJ, Boyd J, Foulkes WD: Impact of BRCA1 mutations and over expression of p53 on prognosis and response to treatment following breast carcinoma: 10-year follow up data. Cancer 2003, 97:527-536.

15. Robson ME, Chappuis PO, Satagopan J, Wong N, Boyd J, Goffin JR, Hudis C, Roberge D, Norton L, Begin LR, Offit K, Foulkes WD: A combined analysis of out come folowing breast cancer: differences in survival based on BRCA1/BRCA2 mutation status and adminstration of adjuvant treatment. Breast Cancer Res 2004, 6:R8-R17.

16. Foulkes WD: Clinically relevant biology of hereditary breast cancer. Semin Oncol 2007, 34(5):379-383.

17. Klopfleisch R, Gruber AD: Increased expression of BRCA2 and RAD51 in lymph node metastases of canine mammary adenocarcinomas. Vet Pathol 2009, 46(3):416-422.

18. von Euler $\mathrm{H}$ : Tumors of the mammary glands. In 3rd ed of the British Small Animal Veterinary Association (BSAVA) Manual of Canine and Feline Oncology, Volume 16. Edited by Dobson JM, Lascelles BDX. ; 1996:237-247.

19. Lavelle GE, De Campos CB, Bertagnolli AC, Cassali GD: Canine malignant mammary gland neoplasms with advanced clinical staging treated with carboplatin and cyclooxygenase inhibitors. In Vivo 2012, 26(3):375-379.

20. Betz D, Schoenrock D, Mischke R, Baumgärtner W, Nolte I: Postoperative treatment outcome in canine mammary tumors: Multivariate analysis of the prognostic value of pre- and postoperatively available information. Tierärztl Prax Ausg K Kleintiere Heimtiere 2012, 40(4):235-242 [Article in English, German].
21. Guadagni F, Ferroni P, Carlini S, Mariotti S, Spila A, Aloe S, D'Alessandro R, Carone DM, Cicchetti A, Riccitti A, Venturo I, Perri P, Filippo FD, Cognetti F, Botti C, Roselli M: A reevaluation of carcinoembryonic antigen CEA as a serum marker for breast cancer: a prospective longitudinal study. Clin Cancer Res 2001, 7:2357-2362.

22. Ali SM, Leitzel K, Chinchilli VM, Engle L, Demers L, Harvey HA, Carney W, Allard JM, Lioton A: Relationship of serum HER-2/neu and serum CA 15-3 on patients with metastatic breast cancer. Clin Chem 2002, 48:1314-1320.

23. Novaro V, Radisky DC, Castro NE, Weisz A, Bissell MJ: Malignant mammary cells acquire independence from extracellular context for regulation of estrogen receptor alpha. Clin Cancer Res 2004, 10:402-409.

24. He Q, Fornander T, Johansson H, Johansson U, Hu GZ, Rutqvis LE, Skog S: Thymidine kinase 1 in serum predicts increased risk of distant or loco-regional recurrence following surgery in patients with early breast cancer. Anti Cancer Res 2006, 26:4753-4759.

25. Chang CC, Tsai MH, Liao JW, Chan JP, Wong ML, Chang SC: Evaluation of hormone receptor expression for use in predicting survival of female dogs with malignant mammary gland tumors. J Am Vet Med Assoc 2009, 235:391-396.

26. Hsu WL, Huang HM, Liao JW, Wong ML, Chang SC: Increased survival in dogs with malignant mammary tumours overexpressing HER-2 protein and detection of a silent single nucleotide polymorphism in the canine HER-2 gene. Vet J 2009, 180:116-123.

27. Campos LC, Lavalle GE, Estrela-Lima A, JC M dF, Guimaraes JE, Dutra AP, Ferreira E, de Sousa LP, Rabelo EML, AFD V dC, Cassali GD: CA 15.3, CEA and LDH in dogs with malignant mammary tumors. J Vet Intern Med 2012, 26:1383-1388

28. Eriksson S, Munch-Petersen B, Johansson K, Eklund $\mathrm{H}$ : Structure and function of cellular deoxyribonucleoside kinases. Cell Mol Life Sci 2002, 59:1327-1346.

29. Sherley $\lrcorner$, Kelly $T \mathrm{~J}$ : Regulation of human thymidine kinase during the cell cycle. J Biol Chem 1988, 263:8350-8358.

30. Von Euler H, Eriksson S: Comparative aspects of the proliferation marker thymidne kinase 1 in human and canine tumor diseases. Vet Comp Oncol 2011, 9:1-15.

31. Gronowitz JS, Hagberg H, Kallander CF, Simonsson B: The use of serum deoxythymidine kinase as a prognostic marker, and in the monitoring of patients with non-Hodgkin's lymphoma. Br J Cancer 1983, 47:487-495.

32. Hallek M, Langenmayer I, Nerl C, Knauf W, Dietzfelbinger H, Adorf D, Ostwald M, Busch R, Kuhn-Hallek I, Thiel E, Emmerich B: Elevated serum thymidine kinase levels identify a subgroup at high risk of disease progression in early, nonsmoldering chronic lymphocytic leukemia. Blood 1996, 93:1732-1737.

33. O'Neill KL, Zhang F, Li H, Fuja DG, Murray BK: Thymidine kinase 1 - A prognostic and diagnostic indicator in ALL and AML patients. Leukemia 2007, 21:560-563.

34. Von Euler H, Einarsson R, Olsson U, Lagerstedt AS, Eriksson S: Serum thymidine kinase activity in dogs with malignant lymphoma: a potent marker for prognosis and monitoring the disease. J Vet Int Med 2004, 18:696-702.

35. Von Euler H, Rivera P, Aronsson AC, Bengtsson C, Hansson LO, Eriksson S: Monitoring therapy in canine malignant lymphoma and leukemia with serum thymidine kinase 1 activity - evaluation of a new, fully automated non-radiometric assay. Int J Oncol 2009, 34:505-510.

36. Sharif $H$, Von Euler $H$, Westberg $S$, He E, Wang L, Eriksson S: A sensitive and kinetically defined radiochemical assay for canine and human serum thymidine kinase 1 (TK1) to monitor canine malignant lymphoma. Vet $J$ 2012, 194:40-47.

37. Kiran Kumar J, Sharif H, Westberg S, Von Euler H, Eriksson S: High levels of inactive thymidine kinase 1 polypeptide in sera from dogs with solid tumours by immunoaffinity methods: Implications for in vitro diagnostics. Vet J 2013, 197(3):854-860.

38. Hanan S, Jagarlamudi KK, Wang L, He E, Eriksson S: Quaternary structures of recombinant, cellular, and serum forms of Thymidine Kinase 1 from dogs and humans. BMC Biochem 2012, 13:12.

39. Karlstrom AR, Neumuller M, Gronowitz JS, Kallander CF: Molecular forms in human serum of enzymes synthesizing DNA precursors and DNA. Mol Cell Biochem 1990, 92:23-35.

40. He Q, Zou L, Zhang PA, Liu JX, Skog S, Fornander T: The clinical significance of thymidine kinase 1 measurement in serum of breast cancer patients using anti-TK1 antibody. Int J Biol Marker 2000, 15:139-146. 
41. Zhang F, Li H, Pendleton AR, Robison JG, Monson KO, Murray BK, O'Neill KL: Thymidine kinase 1 immunoassay: A potential marker for breast cancer. Cancer Detect Prev 2001, 25:8-15.

42. Klopfleisch R, Lenze D, Hummel M, Gruber AD: Metastatic canine carcinomas can be identified by gene expression profile that partly overlaps with human breast cancer profiles. BMC Cancer 2010, 10:618. doi: 10.1186/1471-2407-10-618.

43. Pawlowski KM, Maciejewski H, Dolka I, Mol JA, Motyl T, Krol M: Gene expression profiles in canine mammary carcinomas of various grades of malignancy. BMC Vet Res 2013, 9:78. doi: 10.1186/1746-6148-9-78.

44. Pawlowski KM, Maciejewski H, Majchrzak K, Dolka I, Mol JA, Motyl T, Krol M: Five markers useful for the distinction of canine mammary malignancy. BMC Vet Res 2013, 9:138. doi: 10.1186/1746-6148-9-138.

45. Munch-Petersen B: Differences in the kinetic properties of thymidine kinase isoenzymes in unstimulated and phytohemagglutinin-stimulated human lymphocytes. Mol Cell Biochem 1984, 64:173-185.

doi:10.1186/s12917-014-0228-

Cite this article as: Jagarlamudi et al.: Properties of cellular and serum forms of thymidine kinase 1 (TK1) in dogs with acute lymphocytic leukemia (ALL) and canine mammary tumors (CMTs): implications for TK1 as a proliferation biomarker. BMC Veterinary Research 2014 10:228

\section{Submit your next manuscript to BioMed Central and take full advantage of:}

- Convenient online submission

- Thorough peer review

- No space constraints or color figure charges

- Immediate publication on acceptance

- Inclusion in PubMed, CAS, Scopus and Google Scholar

- Research which is freely available for redistribution 